\title{
Das »Gesellschaftlich-Komische«
}

Zu Komik und Komödie am Beispiel der Stücke

und Bearbeitungen Brechts

\author{
INAUGURAL-DISSERTATION \\ zur \\ Erlangung des Grades eines Doktors der Philosophie \\ dem Fachbereich Germanistik \\ der \\ Freien Universität Berlin
}

vorgelegt

von

PETER CHRISTIAN GIESE

aus Friedland (Niederlausitz)

Berlin 1972 
ISBN 978-3-476-99936-8

ISBN 978-3-476-99935-1 (eBook)

DOI 10.1007/978-3-476-99935-1

Referenten: Prof. Dr. Heinz Hillmann

Prof. Dr. Anke Bennholdt-Thomsen

Tag der mündlichen Prüfung: 13. März 1973 


\section{INHALT}

Vorbemerkung . . . . . . . . . . . . . . . . . . . . . 1

Literaturbericht. Problemstellung. Thesen . . . . . . . . . . . . 3

Brechts frühe Einakter . . . . . . . . . . . . . . . . . . 21

Valentin-Einfluß? - Zum Formtypus Einakter - Der Bettler oder Der tote Hund: ein zur Szene gestreckter Witz - Der Fischzug: ein naturalistischer Schwank Er treibt einen Teufel aus: eine Farce - Lux in Tenebris: eine Kabarettnummer Die Kleinbürgerhochzeit. Analyse des Komödiencharakters. Zum Personal. Die Komik des anständigen Benehmens. Spätbürgerliche Familie und frühbürgerliche Idylle. Das Motiv der zerfallenden Möbel. Zum Problem Satire - Zusammenfassung.

Komisches, Komödie und verwandte Phänomene bei Brecht . . . . . 38

I. Zum Problem des Grotesken und Absurden . . . . . . . . . . 38

Das Groteske ist nicht das Absurde - Die groteske "Nummer* als spezifische Erscheinungsform des Komischen - Die Clownsnummer im Badener Lebrstück Der Montageakt in Mann ist Mann - Die Groteskszenen in Mabagonny - Die Ausnahme: Groteske als Zustandsschilderung in Furcht und Elend - Rein funktionaler Charakter des Grotesken in den Faschismus-Stücken - Die Groteske als Verkürzung der Komödie (Dürrenmatt). Komödie durch gesellschaftliche Perspektive (Brecht).

II. Zum Problem des Tragikomischen . . . . . . . . . . . . .

Das Schreckliche, Ernste, Traurige etc. ist nicht das Tragische - Die ernsten Szenen heben die Intention Komödie nicht auf (Arturo Ui).

III. Notizen zu einzelnen Problemen . . . . . . . . . . . . . Zum Verhältnis von Komik und Verfremdung - Illusionsdurchbrechung - Historisierung - Parodie, Travestie - Humor - Satire. Ihre perspektivische Differenz zur Komödie - Trommeln in der Nacht. Komödie. Mann ist Mann. Lustspiel: Lustspiel oder Komödie?

Das »Gesellschaftlich-Komische«. Motive und Szenen . . . . . . . .

I. Autonomie und Funktion einer komischen Szene: Die Familienfeier (Verlobung und Hochzeit). . . . . . . . . . . . . . . . .

Analyse der entsprechenden Szenen in: Trommeln in der Nacht - Kuble Wampe Im Dickicht der Städte - Die Dreigroschenoper - Der kaukasische Kreidekreis Der gute Mensch von Sezuan - Herr Puntila und sein Knecht Matti.

II. Komik und "Materialismus" . . . . . . . . . . . . . . .

Brechts Begriff des "primitiven Materialismus«. Seine Funktion in der Dreigroschenoper - Der hedonistische Impetus. Baal und das Glücksgott-Fragment Primitiver Materialismus als negativ-komisches Motiv. 
III. "Entfremdung" als komisches Motiv. Die Doppelrolle . . . . . .

Die "Normalität « der Prostitution als komisches Motiv - Die Doppelrollen in: Der gute Mensch von Sezuan - Die sieben Todsünden der Kleinbürger - Herr Puntila und sein Knecht Matti - Das wirkliche Leben des Jakob Geberda.

IV. Das komische Exempel .

Zum Charakter des komischen Exempels allgemein - Besondere Motive: Rechtsprechung - Konformismus - Künstler und Intellektuelle in der bürgerlichen Gesellschaft - Andere komische Exempla - Zusammenfassung.

Molière - Lenz - Brecht. Komödie, Bearbeitung, Brecht-Komödie . . .

I. Komödie und Bearbeitung . . . . . . . . . . . . . . . .

Die "vermittelte A Aktualität. Zur Problematik des Bearbeitungstypus und der Brechtschen Komödie - Zum Problem der Tradition. »Kulturelles Erbe* und/ versus »heitere Verabschiedung der Vergangenheit $*$.

II. Molières »Dom Juan" und Brechts Bearbeitung . . . . . . . . .

Komödiencharakter und gesellschaftlicher Gehalt des Molièreschen Dom Juan. Comédie de caractère. Ideologie der noblesse de cour - Brechts Kommentare zu Molière - Zur Charakterisierung Don Juans bei Molière und bei Brecht. Kritik der Brechtschen Konzeption eines feigen Don Juan. Das »Gesellschaftlich-Komische» der Molièreschen Dom Juan-Figur. Kleiner Exkurs zur Bettlerszene - Don Juans Relation zu den Adligen - Don Juans Relation zu den unteren Ständen - Das Herr-Knecht-Verhältnis, mit einem Exkurs zu den Dienern in der europäischen Komödie - Zur Möglichkeit positiver Aspekte der Don Juan-Figur - Die Don JuanBearbeitung als Brecht-Komödie.

III. „Der Hofmeister «. Komödie von Lenz - Komödie von Brecht .

Zur Besonderheit und Wirkung des Brechtschen Hofmeisters - Die Gattungsfrage, von Brecht her gesehen. Der Begriff der »deutschen Misere « - Das Gattungsproblem, von Lenz her gesehen. Lenzens theoretische Außerungen zur Komödie - Zu Titel und Personenverzeichnis des Lenzschen Hofmeister - Analyse des Komödiencharakters und des gesellschaftlichen Gehalts des Lenzschen Hofmeister. Erziehung als Komödienthema. Zur Rolle des Geldes. Der Geheime Rat ist nicht die "große Ausnahme«. Zur Figur des Wenzeslaus. Das demonstrative happy ending und die bürgerliche Utopie vom Klassenkompromiß - Kritik der spätbürgerlichen Hofmeister-Interpretation. Die Legende von Tragikomödie und ihr ideologischer Gehalt - Die Hofmeister-Bearbeitung als Brecht-Komödie. Die typischen Motive.

IV. Die "Deutsche Misere« - Das geheime Leitmotiv von Komik und Komödie bei Brecht

Zum historischen Standort und zum politischen Gehalt des Komischen bei Brecht. Die tabuisierte "deutsche Misere «: die spezifische Relation zur Vergangenheit in der Brechtschen Komödie contra offizielles Geschichtsbild und Kulturpolitik der DDR.

Anmerkungen . . . . . . . . . . . . . . . . . . . . .

Literaturverzeichnis . . . . . . . . . . . . . . . . .

Register 
Wenn die Philosophie ihr Grau in Grau malt, dann ist eine Gestalt des Lebens alt geworden, und mit Grau in Grau läßt sie sich nicht verjüngen, sondern nur erkennen; die Eule der Minerva beginnt erst mit der einbrechenden Dämmerung ihren Flug.

G. W. F. HEGEL

In den Zeiten der Umwälzung, den furchtbaren und fruchtbaren, fallen die Abende der untergehenden Klassen mit den Frühen der aufsteigenden zusammen. Dies sind die Dämmerungen, in denen die Eule der Minerva ihre Flüge beginnt.

BERTOLT BRECHT

Die Geschichte ist gründlich und macht viele Phasen durch, wenn sie eine alte Gestalt zu Grabe trägt. Die letzte Phase einer weltgeschichtlichen Gestalt ist ihre Komödie. Die Götter Griechenlands, die schon einmal tragisch verwundet waren im gefesselten Prometheus des Aschylus, mußten noch einmal komisch sterben in den Gesprächen Lucians. Warum dieser Gang der Geschichte? Damit die Menschheit beiter von ihrer Vergangenheit scheide.

KARL MARX

Alle beseitigbaren gesellschaftlichen Unvollkommenheiten gehören nicht in die Tragödie, sondern in die Komödie.

Bertolt BREChT

In der bürgerlichen Gesellschaft herrscht also die Vergangenheit über die Gegenwart, in der kommunistischen die Gegenwart über die Vergangenheit. MarX/Engels

Die Probleme von heute sind vom Theater nur soweit erfaßbar, als sie Probleme der Komödie sind. Alle anderen entziehen sich der direkten Darstellung. Die Komödie läßt Lösungen zu, die Tragödie, falls man an ihre Möglichkeit überhaupt noch glaubt, nicht.

BerTOLT BREChT 